We encourage planting, the labour and capital therein expended may yield returns after the lapse of generations; we, at the same time, allow timber, the growth of ages, to be swept by fire by any one who owns a box of matches, and looks on firing as the best means of subduing the wilderness. We import with great difficulty insectivorous birds, and allow the Apteryginæ and other insectivorous genera to be destroyed without mercy.

Fearing to occupy too mich space, I will only glance at our worst raptorials from which our birds suffer. First, the bond fide settler in his "new chum " phase, before " he has eaten his tutu" (as we say); next, the digger, who kills kivi, kallapo, kalla, and pigeon, without any respect to season; his dog, like that of the settler, being a more fatal enemy to birds than himself. Lastly, the collector, the provider of rarities for museums, \&c. There is no fence month with him ; if spring or summer plumage is interesting, so also is that of winter ; eggs, young, the adult, alike he preys on all. He is heedless of the Mosaic promise; he cares not to have his days prolonged, so that he gets good specimens.

Could we be persuaded to try and avert what will some day be a great reproach to this country, the destruction of so many species of our feathered tribe, D'Urville's Island might be found most useful. Wingless species, and birds of feeble powers of flight, might there find a refuge for some of their representatives. Resolution Island might be placed under tapu from molestation by dog and gun.

Ohinitahi, New Zealand, February 2

\section{The State and Science}

From the position taken by Mr. Gladstone with regard to the Dublin University Bill, from Mr. Lowe's speech at Halifax, and from other indications, it would appear to be the policy of the Government, not to renderaccessibleto all, withoutsectarian distinction, the professorships and other endowments of the Universities, and to assign to modern culture a fair share thereof, bat to abolish all such endowments, and to withdraw all State aid from both literature and science. In favour of such a policy it has been urged not only that it is in accordance with sound political economy to leave every pursuit to seek for itself its own reward, but also that the system of endowment and artificial aid has proved a signal failure. Now, if by this last argument it is meant that the large rewards which have been given for classical knowledge and for mathematical attainments have not been productive of numerous Bentleys, Porsons, and Newtons, the truth and validity of the argument must be admitted. The rewarding of mere acquired knowledge was little likely to show its results in original work. The capacity for acquisition, literary, mathematical, or scientific, is a very different thing from the power of original production, or of extending the boundaries of human knowledge. Probably in some cases the latent spark of genius has even been stifled and smothered by the load of "cram" necessarily superimposed to meet the requirements of exacting examiners. It would be, however, I think, a mistake not to allow some considerable reward to more exact knowledge. But it is with regard to original work and the proved capacity for doing it that external encouragement and reward is ab:olutely necessary. Such work, in most departments of literature and science, cannot possibly, in a commercial sense, pay. It is this work, however, which confers especial honour and advantage on the State. Therefore it is in accordance alıke with justice and sound policy that the doing of such work should be murificently encouraged and rewarded by the State. Such a policy might be reasonably expected to issue in results very different from those which have attended the endowment of "cram." Previous failure cannot be objected, for the attempt can scarcely be said to have ever been made. It behoves, therefore, literary and scientific men to look to it that, in any redistribution of the University or other endowments, the true interests of both science and literature-and especially the encinuragement and reward of original research-are duly regarded by the Government. But a certain superficial political economy may object that such a policy would be of dangerous tendency, inasmuch as it would recognise the existence of the State as a unity, which, being honoured and benefited, should encourage and reward. The honoured and benefited, should encourage and reward. The must he left each for himself, to seek such recompense as he can in the ordinary market. Sir Isaac Newton would not be rewarded by the present Government with the Mastership of the Mint. They have abolished that office. No, they would guard him in his enjoyment of the copyright of the "Principia!" Such, it would seem, according to Messrs. Lowe and Gladstone, is the dictate of common sense, of justice, and of the "sound political economy" of

ADAM SMITH

\section{Brilliant Meteor}

I NOTICED in your number for last week the account of a brilliant meteor, observed in Cumberland on April I9. Now I had reported to me a very similar meteor at nearly the same time (about 8.40 P.M.), an account of which I forwarded, with my other results of the night's watch, to Mr. A. S. Herschel, who would gladly receive any further report of the same; unfortunately, I have not that number of NATURE at hand, and therefore cannot make a personal application to your correspondent. On the same evening, about 10.7, I myself saw an exceedingly brilliant meteor, which fell to a point just $S$. of Vega. It is curious that both of these come from the radiant situated about R.A. I55, D + 47, or rather from one of the group of radiants there situated, $\mathrm{M}_{8}$ of Heis, 56 and $5^{2}$ of Schiaparelli. It would be an interesting point of investigation whether the meteors from that radiant are of peculiar brightness.

$$
\text { 20, Bootham, York, April 3o J. EDMUND CLARK }
$$

\section{EXPERIMENTAL ILLUSTRATIONS OF MUSICAL TONE}

R EFERENCE was recently made in these columns to an educational lecture on "Musical Tone," delivered by me on March $\mathrm{r}_{4}$, at the Taunton College School. Among the experiments, several were specially arranged in connection with this lecture, and these I should be glad to put on record as simple and inexpensive means of illustrating important points.

For the purpose of displaying the relation between the "quality" of musical tones and the kind of vibration producing them, a series of magic-lantern slides were shown. These were prepared in the ordinary way, being smoked glass plates on which vibration-lines were traced by points attached to tuning-forks, pianowires, \&c. Each tone being sounded as its vibrationline was shown, the audience was enabled to appreciate clearly the difference between the simple tone of the tuning-fork and the clangs of a stringed instrument, played on musically and also made to shriek and rasp. For an extreme illustration, to show the relation of an irregularly discordant clang to an irregularly bent and jagged vibration-line, a toy popularly known as a "Bismark's Whistle" was made, larger than the usual size. It consisted of a tin-plate canister, near the centre of the bottom of which a piece of gut, knotted at the end, was passed through a small hole. Well-resined fingers drawn with a tight grip along the gut caused this infernal machine to emit a hideous sound, the vibrationline of which was shown as taken off on the smoked glass from a pointed wire soldered to the bottom of the canister.

The pictorial representation of a beat is of course indispensable to explain Helmholtz's theory of harmony and dissonance. As, however, neither the plan used by Prof. Helmholtz of taking off the beats of two organ pipes by means of a vibrating membrane, nor the splendid arrangement of Lissajou's method employed by Prof. Tyndall, were readily available, I found it necessary to contrive a simpler and coarser method. Accordingly, two stout piano-wires were stretched side by side on a board about three inches apart, and connected near the middle by a bent yoke of thinner wire, term!nating upwards in a point. The two wires being tuned so as to give beats at a convenient rate, the alternate phases of addition and subtraction of the vibrations of the two wires, corresponding to the beats, were well 
shown by the central pointer, from which pictures of the beats were taken off on the smoked glass, forming admirable slides.

Mr. R. Knight, of Wellington, who superintended the making of the apparatus, devised a neat arrangement for showing the lengths of resorfant tubes (See Tyndall, Lecture V.). It consists of a 4 -ft. length of 3 -inch zinc tube mounted upright on a foot and nearly filled with water, so as to form a cistern in which a 2 -in. tube is raised and lowered, answering at the proper height with powerful resonance to a large tuning-fork. This apparatus will, I expect, come into use in fuicure as the most convenient means of demonstrating the principle of lengths of organ-pipes. When the instrument is used for class purposes, it may be recommended that the tube be graduated to quarters of an inch, so that the pupils may be practised in calculating the wave-length, and thence the pitch, of any tuning-fork tested by the resonant tube. Further, with reference to the theory of musical pipes, it may be worth while to mention that an 8 - $\mathrm{ft}$. length of $\frac{3}{4} \mathrm{in}$. iron gas tube serves well to produce the overtones of open pipes. It is best to fit some kind of trumpet mouth-piece at one end, by means of which the most elementary musical scale, that of simple trumpet-music, may be effectively given.

No ready way being found of displaying Sir. C. Wheatstone's kaleidophone experiments on a large scale, they were shown afterwards as table experiments. Since then, however, a Chinese joss-stick has supplied the means of showing to an audience the path of the end of a vibrating rod. A piece of the lighted stick attached to the end of an umbrella rib shows beautifully convoluted figures several inches across. Any other means of attaching a bright permanent spark may of course be used, and the plan serves also to show the path of a point on a long vibrating wire. The experiment of waving a large tuningfork to and fro while in vibration, which Mr. Sedley Taylor described in NATURE, vol. v. p. $32 \mathrm{I}$, had also been noticed by us. For want of means of making the result visible at a distance, it was not shown in the lecture. An inch of lighted joss-stick, however, fixed transversely near the end of one leg, shows well the contrast between the line of light traced by waving the fork in its quiescent state, and the series of dots of light into which this line is resolved when the fork is waved or swung while in vibration, its counteracting movements bringing it to momentary rest.

\section{E. B. TYLOR}

\section{ON THE SULPHUROUS IMPURITY IN COAL}

\section{GAS*}

THE lecturer commenced by stating the origin of the sulphurous impurity in coalgas to be the iron pyrites which is contained in coal, and that in the manufacture of gas, when the coal is strongly heated, the sulphur of the iron pyrites not only combines with hydrogen to form the gaseous sulphuretted hydrogen, but also with carbon, to form the very volatile liquid bisulphide of carbon.
Little need be said of the desirability of removing the sulphur from coal gas, for in many of our large libraries, such as that of the Athenæum Club, the injurious effect of the sulphurous and sulphuric acids produced by the combustion of gas containing sulphur, seems to be plainly manifest, more especially on the leather binding of the books. The gas, after leaving the retorts in which the coal is heated, is cooled down, and passed through towers filled with coke, over which water is kept trickling. By these means a considerable proportion of the sulphur is

* Abstract of a Lecture delivered at the Royal Institution on February $x y$, by A, Veroon Harcourt, F, R. S. removed in the form of sulphide of ammonium. It was shown by experiment that this washing with water could only be employed to a limited extent; as by excessive "scrubbing," as it is technically termed, the gas is greatly deteriorated as to its illuminating power. The sulphuretted hydrogen remaining in the crude gas is easily removed; but the removal of the bisulphide of carbon is attended with so many difficulties that up to the present time no satisfactory process has been devised to effect this purpose. The lecturer exhibited strikingly the two methods used for the removal of the sulphuretted hydrogen, one by passing the gas over lime, and the second by passing the gas over oxide of iron, and stated that it is comparatively rare to find any of this impurity in the gas as supplied to consumers. Up to the present time no process is used for the removal of the bisulphide of carbon. Mr. Harcourt has, however, found that by heating a mixture of bisulphide of carbon vapour and hydrogen to redness, the former is decomposed into sulphuretted hydrogen. It will be thus seen that the removal of the bisulphide of carbon from coal gas is rendered possible, for by simply heating the gas to redness the sulphur combines as before with hydrogen to form sulphuretted hydrogen, which can be easily removed by passing through a purifier containing oxide of iron. In this way, by passing coal gas, which contained 30 grains of sulphur in 100 cubic feet, through a red hot tube, and then through an iron purifier, the sulphur was reduced to about 5 or 6 grains in 100 cubic feet. It might be imagined that the passage of coal gas through a red hot tube would deteriorate its quality; but Mr. Harcourt's experiments show that the contrary is the case, for by passing gas of $14^{\circ}$. I candles rapidly through a tube heated to moderate redness, the illuminating power was found to be $15 . \mathrm{I}$ candles, and after passing through a tube heated to bright redness, its illuminating power was increased to 16.66 candles. A parallel case to this is seen when marsh gas is decomposed into hydrogen and carbon by a series of electric sparks, the gas which is obtained occupies almost twice the original volume of the gas, but possesses a far greater illuminating power than that of the original marsh gas, owing to the presence of a small quantity of acetylene or some such body. It will be seen that these experiments offer what certainly seems to be a feasible process for the great reduction of the amount of sulphur contained in coal gas.

\section{PROPOSED OBSERVATORY IN NEW ZEALAND}

N Dec. 16,1850 , the first ship-load of emigrants, under the auspices of the Canterbury Association, landed at Port Lyttelton and commenced the foundation of the present province of Canterbury. On Dec. I6, I 871 , the settlement attained its twenty-first year, and it was felt by a large number of gentlemen here that it would be well to celebrate the majority of the province by some permanent memorial. A meeting was held on that day, attended by a number of the most influential residents ; and it was unanimously resolved to form an association for the establishment of an astronomical observatory near Christchurch. It was remarked by several speakers that this province possesses considerable advantages for such an institution. Between the ocean on the east and the great range of the Southern Alps on the west, there stretches an expanse of unbroken plain more than 100 miles in length and 50 in breadth. The remarkable clearness of the atmosphere, joined to this large extent of level land, renders it possible to observe a much larger area of the heavens than is usually the case. The meeting fully endorsed the remarks of the promoters of 